San Jose State University

SJSU ScholarWorks

2006

\title{
The Relationship Between Health Beliefs and Adherence to Treatment of Russian Immigrants with Hypertension
}

Michael R. Kolesnikov

San Jose State University

Follow this and additional works at: https://scholarworks.sjsu.edu/etd_projects

Part of the Other Nursing Commons

\section{Recommended Citation}

Kolesnikov, Michael R., "The Relationship Between Health Beliefs and Adherence to Treatment of Russian Immigrants with Hypertension" (2006). Master's Projects. 774.

DOI: https://doi.org/10.31979/etd.tdg8-gsh9

https://scholarworks.sjsu.edu/etd_projects/774

This Master's Project is brought to you for free and open access by the Master's Theses and Graduate Research at SJSU ScholarWorks. It has been accepted for inclusion in Master's Projects by an authorized administrator of SJSU ScholarWorks. For more information, please contact scholarworks@sjsu.edu. 
SAN JOSE STATE UNIVERSITY

SCHOOL OF NURSING

MASTER'S PROGRAM PROJECT OPTION (PLAN B) PROJECT SIGNATURE FORM

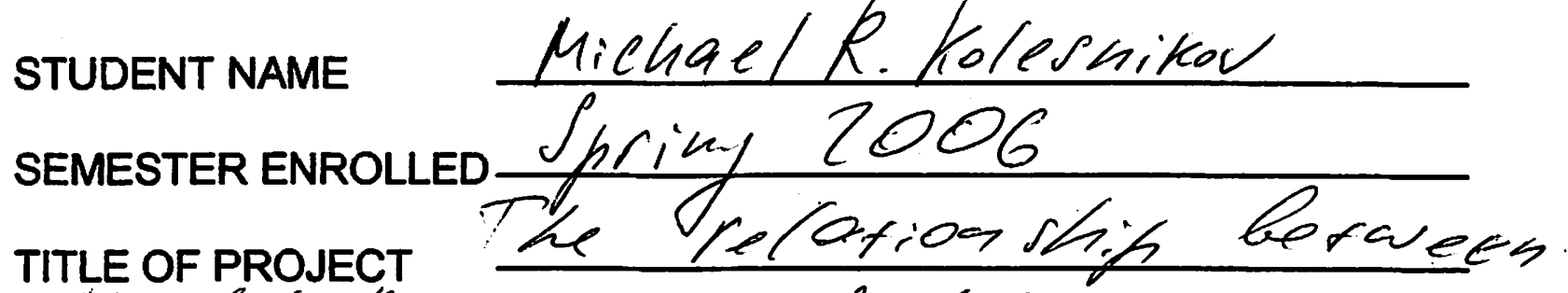

Health beliefs and Adherence to

Treathout of Russian tmmipeanos with Hypedtempion

name of Journal Public Hellos Nursing

The project and manuscript have been successfully completed and meet the standards of the School of Nursing at San Jose State University. The project demonstrates the application of professional knowledge, clinical expertise, and scholarly thinking. An abstract of the project and two copies of the manuscript are attached.

Chinking. Ines,

ADVISOR'S SIGNATURE

marian Ty Ceder

ADVISOR'S SIGNATURE

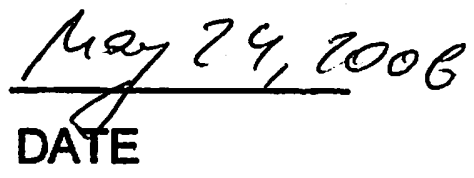

DAT 24,2006

Please submit this form to the Graduate Coordinator. Attach abstract, two copies of the manuscript, and documentation of submission to the journal (i.e., postal receipt).

JHC: Spring, 2000 
THE RELATIONSHIP BETWEEN HEALTH BELIEFS AND ADHERENCE TO

TREATMENT OF RUSSIAN IMMIGRANTS WITH HYPERTENSION

Michael R. Kolesnikov, MSN, RN

Chia-Ling Mao, Ph.D., RN
Associate Professor
School of Nursing
San Jose State University

Marian K. Yoder, Ed.D., RN

Professor

School of Nursing

San Jose State University 


\begin{abstract}
Introduction: Hypertension (HTN) has been identified as a common health problem in every ethnic group in the USA. Due to the silent nature of the HTN, some cultures may not perceive this condition as being serious or potentially fatal.

Objective: The purpose of this study was to investigate the health beliefs of Russianspeaking immigrants with hypertension and their adherence to the prescribed treatment. Design: The study was a non-experimental exploratory survey and interview. Convenience sampling was used. The Health Belief Model (HBM) provided the theoretical framework.

Sample: A total of 62 subjects ( $27 \%$ male and $73 \%$ female, ages from 51 to 86 ) completed the questionnaire that covered health beliefs and self-report on adherence to treatment.
\end{abstract}

Results: This study indicated a correlation between embarrassment, inconvenience, and compliance with fitness recommendations. Financial burden correlated with adherence to dietary modifications. A strong negative correlation was found between perceived severity of complications and number of missed medications. Patient's awareness about existence of complications of hypertension had a positive correlation with change in adherence to treatment. Educational level had no correlation with adherence.

Conclusion: Health education based on these findings will facilitate the reduction of the rate of complications in the targeted population.

Key words: Russian immigrants, hypertension, health belief model, compliance, adherence 


\section{Introduction}

Hypertension is one of the most explored topics in primary care, yet it is still one of the most challenging conditions to treat. Hypertension is often called a "silent killer" because high blood pressure alone does not cause a significant discomfort to the patient, yet the complications of this condition are often disabling and sometimes fatal (Groer, 2001). There are many medications, treatment schemes, and life style modifications available to the healthcare provider for dealing with the patient's hypertension problem, but one of the most challenging obstacles to overcome is the patient's lack of adherence to the prescribed treatment.

The purposes of this study were (a) to assess health beliefs of Russian-speaking hypertensive patients towards complications of hypertension by the use of Health Belief Model (HBM), (b) to measure the patients' adherence rate to treatment through a selfreport questionnaire, and (c) to determine correlations between any of the dimensions of the HBM and adherence rate.

The research question for this study was: What is the relationship between health beliefs of a Russian-speaking patient population towards hypertension and their self reported adherence to treatment?

\section{Background/Literature Review}

The American Heart Association (AHA) recommends that people with hypertension follow strict dietary advice, which includes lowering sodium consumption, substituting fatty foods with low-fat or fat-free choices and increasing the number of daily servings of fruit and vegetables. The AHA also suggests that even light exercises are beneficial for cardiac health if they are done most days of the week. Smoking 
cessation, elimination of caffeine from the diet, and adherence to relaxation techniques were also recommended for better control of the hypertension in addition to pharmacological measures (American Heart Association, 2006a).

There are different types of medications used for treating hypertension. Hansson Lindholm, Ekbom, Dahlof, Lanke, et al., (1999) reported no significant difference between older and newer medications in preventing long-term fatal complications of HTN. This research also suggested that adherence to the treatment plan was the most important factor, which was directly related to the patients' outcomes (Hansson, et al).

According to Nuesch, Schroeder, Dieterle, Martina \& Battegay (2001), some researchers suspect the adherence to the treatment plan is directly related to the efficiency of the blood pressure lowering medication. However, Nuesch and her colleagues found no significant difference in compliance among those who had a pronounced blood. pressure lowering effect and those who had not. These findings suggest that there might be another factor affecting patients' adherence to the treatment plan (Nuesch, et al).

There were very few health-related studies of Russian-speaking immigrants found in the literature. A qualitative study, using a phenomenological approach, conducted by Benisovich \& King (2003), assessed health beliefs of a Russian-speaking population in the San Francisco Bay Area. The researchers found four major themes. The population of interest believes that health could be described as "absence of disease." They also express "distrust to health messages delivered by media," describing them as inconsistent and contradicting their beliefs. Some participants feel "alienated from the US health care system" due to lack of transportation or translators. Russian-speaking immigrants said that in Russia "anti-hypertensive medications are taken once a month in a form of 
injection." This research revealed an important link between hypertension and health beliefs of the targeted population. They may not see an asymptomatic hypertension as a serious illness due to its "silent" nature and their perception of health as the "absence of disease" (Benisovich \& King).

The Health Belief Model (HBM) was chosen as the theoretical framework to guide this research project. Developed in 1952 and published in 1974 by Maiman and Becker (1974), and Rosenstock (1974a), the HBM's original intention was to explain the failure of the preventive care effort in 1950's and 1960's (Brown, 1999). The model assesses subjects' health beliefs, and predicts the likelihood of taking the recommended action. According to the HBM, the perceived susceptibility, severity, and benefits of taking the preventative measures are directly related to the likelihood of taking such measures (Maiman \& Becker, 1974; Rosenstock, 1974). This model has also been used in an attempt to explain health-related decision making in an Iranian patient population by Al-Hassan and Omran (2005).

Using the HBM as guidance, Macrae, Hill, St. John, Ambikapathy, Carner, et al., (1984) developed a 14-item questionnaire, which predicted the likelihood that a person would undergo a screening for bowel cancer. Macrae measured different dimensions of the HBM and established a correlation between perceived barriers, perceived susceptibility, and patient's behavior. According to that study, the HBM accounted for $12 \%$ of the variance in screening behavior. This group also reported that the tool provides test-retest reliability coefficient of 0.87 , high face validity and assessed psychological factors including health beliefs. The original Macrae's questionnaire has been used by Gipsh, Sullivan, and Dietz (2003) to evaluate the attitudes of the Russian-speaking 
patient population toward a colonoscopy. The results support the reliability and validity of using this tool in the Russian immigrants as the targeted population.

There is very limited number of studies located about healthcare of Russianspeaking immigrants in general and about hypertension in particular. In this research, the HBM was used to investigate the correlation between health beliefs of Russian-speaking immigrants with hypertension and their reported adherence to treatment. This study will provide information to develop population-specific recommendations for Primary Care Providers (PCPs). Such recommendations will include problem-oriented and costeffective interventions to increase adherence to treatment in the targeted population. 


\section{Methods}

This study was a non-experimental exploratory survey using a questionnaire, which was adapted from Macrae, Hill, St. John, Ambikapathy \& Carner (1984). There were no interventions in this study and participants received no compensation. The data collection tools included (a) a 14-item survey tool with questions regarding health beliefs and psychological factors adapted from Macrae, (b) a short demographic questionnaire, and (c) an adherence assessment tool designed by the researchers of this study. The questionnaire was written in English and translated into Russian by the primary researcher. The back-translation verification method which gives accurate results for translation and verification of the research tools (Lee, Kim \& Song, 2005) was used by a county certified Russian medical translator in order to ensure the appropriate translation of the tool.

Data collection was conducted in the medical office in Northern California. Patients filled out a questionnaire and were interviewed by the primary researcher. Data analysis was performed by primary researchers, using SPSS software, version 11. Mean values and standard deviations were calculated for the dimensions of HBM. Absolute and relative frequencies were calculated to describe population's characteristics, such as age, gender, education, health practices, and adherence to treatment. Spearman's rho nonparametric test was applied to measure the rank-order association between demographic data, health beliefs, and adherence to different components of the prescribed therapeutic regimen. Pearson's coefficient was calculated to measure a correlation between the number of missed medications and perceived severity of complications of HTN, since linear association between those variables was noticed. Qualitative data were collected 
during this study to find the reasons people change their adherence to the prescribed treatment. The answers were grouped by common themes and presented as frequencies. Permission to conduct this study was granted by a university institutional review board. All the procedures, related to data gathering, storing, and reporting were in compliance with subject's rights stated in the Declaration of Helsinki. 


\section{Results}

\section{Demographic data}

The participants of this study were 62 Russian-speaking immigrants between 51 and 86 years of age, with $80.6 \%$ of them above the age of 70 . Women comprised $72.6 \%$ of the participants and $27.4 \%$ were men. A majority of the population (84\%) had a 4-year college degree or higher. More than half of the participants $(55.9 \%)$ started active participation in treatment within the first year of being diagnosed with HTN. However, $28.8 \%$ started active participation in treatment within $1-5$ years of being diagnosed, and remaining $15.3 \%$ waited up to 25 years before starting active participation in treatment.

\section{Health beliefs and psychological factors}

The level of stress experienced by participants when they think about a possibility of having a complication of HTN was measured by the questionnaire. Some of the participants $(27.4 \%)$ perceived that they felt comfortable, steady or not bothered about the possibility of having a complication of HTN (low stress response). A little over a third of participants $(37.7 \%)$ indicated they felt timid or unsteady (moderate stress response), and the remaining $34.4 \%$ were nervous, worried, unsafe, or even frightened by (high stress response) such a possibility.

Table 1 shows the mean scores (M) and standard deviations (SD) for the components of the Health Belief Model. Individual and cumulative mean scores for barriers were calculated and used for further comparison. One (1.6\%) of participants expressed a belief that the best way to prevent complications of hypertension is to get an occasional IV or a very strong medication to lower the blood pressure when the readings 
are very high. The results showed that $83.3 \%$ of participants have strong external motivation to comply with treatment.

\section{Adherence to treatment and awareness}

Information about health practices of the subjects and their adherence to the prescribed treatment is summarized in Table 2. A majority (69.4\%) of the participants answered the portion about pharmacological compliance. The subjects were asked to provide information about the number of times they (a) take the medications daily, (b) miss medications in an average week, (c) follow the correct interval between medications, (d) take an incorrect dose, and (e) take any additional medications. The sample was divided into three groups according to the level of pharmacological adherence: non-adherence (took medications correctly less than $80 \%$ of time), partial adherence (80\%-99\% of times), and perfect adherence (100\%).

\section{Significant correlations among variables}

Several statistically significant correlations were identified among variables. There is a positive correlation between the number of medications prescribed daily for the subjects and their level of worry about adherence. The increased level of worry, in turn, has a negative effect on their overall adherence and decreases their frequency of exercises. Subjects' level of education correlates only with their frequency of use of reading for relaxation, but has no effect on rate of adherence (see Table 3). 


\section{Discussion and recommendations}

The analysis of the demographic data indicated that the gender distribution of the sample was disproportionate; more than two thirds of the sample were females. This might be explained by the difference in the life expectancy of Russian males and females living in the Russian Federation. The life expectancy of 58.9 years for males and 71.8 years for females were reported by Men, Brennan, Boffetta, and Zaridze (2003). Thus, there were fewer opportunities for Russian men to take an advantage of the American healthcare system.

The majority (71\%) of the sample were babushkas: Russian-speaking ladies, above 60 years of age. In Russian culture, this group is viewed as babysitters who feed and supervise the youngsters in the family and help them with homework. They help with the cooking in the families, and do light housework. In Bay Area most of them live separate from their children, in apartment complexes close to other Russian-speaking immigrants. Many are widowed, and they usually find their social and emotional support in a small group of close friends and extended families. Despite their high educational level and the number of years they lived in the United States, very few of them have a satisfactory level of proficiency in reading, writing, and speaking English. It is advisable to have a medical translator to accompany the patients if PCP does not speak Russian. It is also important to have all the visual and written materials in Russian language because this provides patients with information in their native language and helps to eliminate the perception of being alienated from US healthcare system, as reported by Benisovich \& King (2003). In addition, this promotes trust between patient and PCP. 
A small portion of the sample (13\%) had a low perceived severity of complications. These participants believed that having a complication of HTN will have no more than moderate effect on their life. The results of the statistical analysis revealed that there is a negative correlation between perceived severity of complications and the number of missed medications. Those participants did not realize the seriousness of having a complication of HTN. Patient education should emphasize the catastrophic effects of complications of HTN and, as a result, it may improve pharmacological adherence.

As reported by Benisovich \& King (2003), many Russian-speaking immigrants lack trust of healthcare officials and healthcare messages. The findings of this study support this statement: the subjects mentioned that positive change in their adherence occurred after they have switched to a trustworthy PCP. A successful HTN management program requires that a PCP establish trust with the patients (Saounatsou, Patsi, Fasoi, Stylianou, Kavga, et al., 2002). It is important that the PCP takes into account their high educational level when explaining to Russian-speaking patients the nature of hypertension, its complications, and the physiological and pharmacological basis of treatment. This requires that the PCP provides teaching that matches the patients' knowledge levels and establishes rapport between the PCPs and the patients. According to American Heart Association (AHA) guidelines, dietary changes for someone with hypertension include lowering the amount of sodium and fat in the diet and increasing consumption of fruit and vegetables. Less than half (48.4\%) of participants recalled this advice in full (see Table 2). The results of the statistical analysis indicated a significant correlation between the financial burden and the attempt to comply with low- 
salt and low-fat dietary changes. It is important to provide education on cost-effective techniques to modify common food recipes for this population.

Caffeine consumption presents a challenge in this population. Typically, Russianspeaking immigrants drink tea or coffee two to three times a day. It is considered a social habit and most conversations happen over a cup of tea or coffee. However, it is surprising that $56.5 \%$ of participants reported that they do not drink caffeinated beverages. One person commented "I drink only green tea, because it is lower in caffeine content than black tea" and another mentioned, "I drink only instant coffee, because it has less caffeine than regular coffee." According to Barone and Roberts (1996), some types of regular coffees have slightly higher caffeine content than instant coffees, and some types of black teas have slightly higher caffeine content than green teas. However, this type of substitution is therapeutically ineffective, because the amount of caffeine still be very high in green teas, as well as in instant coffees. Hence, the dietary education for this patient population should include information about caffeine content in green tea, black tea, instant coffee, and encourage low-caffeine/herbal alternatives to this culturally important habit.

The AHA criteria were used to assess the fitness status of the subjects. These guidelines recommend moderate/heavy exercises for 30-45 minutes a day most days of the week (American Heart Association, 2006b). Over a half of the subjects (53.2\%) reported doing only light exercises and $67.3 \%$ were doing the exercises 4 or more times per week. Thirteen subjects ( $21 \%$ ) omitted the question about frequency of exercises, which may suggest that they either do not consider the question important, or do not exercise regularly. The results of the statistical analysis show a negative correlation 
between embarrassment, inconvenience and frequency of physical exercises (see Table 3). A group exercise program would be very beneficial for this population since it may (a) facilitate social activities among Russian-speaking immigrants, (b) reduce the embarrassment, (c) increase popularity of fitness, and (d) promote a healthy lifestyle. This further develops a culture of exercise and may be passed on to the Russian-speaking community. This may contribute to improved adherence to treatment regimen in the targeted population.

In the literature the rate of LVH in hypertensive patients is reported to be between $22 \%$ and $60 \%$ (Liebson, Grandits, Prineas, Dianzumba, Flack, et al., 1993). However, in this study few (13.3\%) of the subjects were aware of having this complication. The expected rate of $\mathrm{LVH}$ in this population is much higher, because it is a natural progression of the disease, and on average the subjects were diagnosed with HTN for 17 years. The results of statistical analysis showed that the reported rate of LVH has a positive correlation with perceived benefits of treatment. Increasing patients' awareness of existing complications may enhance their perception of the benefits of treatment if the link between hypertension and these conditions is made obvious. It is recommended that patients are made aware of progression of the hypertension, such as existence of the LVH or elevated creatinin, in order to boost their perception of the benefits from treatment.

Based on the findings a high number of medications prescribed to the patients increased their level of anxiety. A higher level of anxiety about adherence to the treatment regimen lowered their frequency of exercises and overall adherence. Therefore, keeping the medication regimen as simple as possible is very important for this patient population. 


\section{Limitations of the Study}

The convenience sample was a limitation of this study. Some trends and health beliefs of Russian-speaking immigrants were underrepresented in this research because the information was obtained from a group of volunteers who regularly visit a PCP. A better representation of Russian-speaking community could be obtained by having part of this study done in non-medical settings, such as Russian stores, pharmacies, Jewish Community Center. All aspects of compliance were self-reported in this survey. Psychological components, such as the social desirability and honesty of the participants, or their own perception of their effort, could affect the results. Future researchers might use objective tools, such as pill count, for more accurate information.

\section{Conclusions}

This study is focused on the health beliefs and adherence to treatment of hypertension among babushkas, who have limited proficiency in reading, writing, and speaking English. The knowledge deficit has been identified as the major problem among this population. The delay of treatment of hypertension was obvious; some of the patients were waiting up to 25 years before starting an active participation in treatment. One third of the patients didn't realize the seriousness of having complications of HTN. Their perceptions about treatment and follow up of HTN were incorrect. Additionally, more than a third of the population did not comply with the pharmacological component of treatment at the appropriate level.

This study suggests that establishing a rapport between patients and PCPs is a crucial component in care of Russian-speaking immigrants. PCPs should appeal to the educational level of the patients, provide written information in their native language, and 
rely on the use of translators. Cultural considerations should be included when providing care for this population. It may be more beneficial to provide health education and do exercises in a group format. Finally, the potential influence of the babushkas' modified health beliefs and healthcare practices should not be underestimated because it may precipitate a change in the Russian-speaking immigrant community. 


\section{References}

Al-Hassan, M. A. \& Omran, S. M. (2005). The effect of health beliefs on health careseeking decision of Jordanian participants with myocardial infarction symptoms. International Journal of Nursing Practice, 11, 13-20.

American Heart Association. (2006a) High blood pressure -- what can be done. Retrieved April 14, 2006 from http://www.americanheart.org/presenter.jhtml?identifier $=4630$

American Heart Association. (2006b) Physical Activity and Cardiovascular Health Fact Sheet. Retrieved April 14, 2006 from http://www.americanheart.org/presenter.jhtml?identifier $=820$

Barone, J. J, Roberts, H. R. (1996). Caffeine Consumption. Food Chemistry and Toxicology, 34, 119-129.

Benisovich, S. V. \& King, A. C. (2003). Meaning and knowledge of health among older adult immigrants from Russia: A phenomenological study. Health Education Research, 18, 135-144

Brown, K.M. (1999) Health Belief Model. Retrieved April 14, 2006 from http://www.med.usf.edu/ kmbrown/Health_Belief_Model_Overview.htm

Gipsh, K., Sullivan, J. M. \& Dietz, E. O. (2004). Health belief assessment regarding screening colonoscopy. Gastroenterology Nursing, 27, 262-267

Groer, M. (2001) Hypertension. In M. W. Groer, (Ed.). Advanced pathophysiology: Application to clinical practice (pp. 285-307). New York: Lippincott. 
Hansson, L., Lindholm, L. H., Ekbom, T., Dahlof, B., Lanke, J., \& Schersten, B. (1999). Randomized trial of old and new antihypertensive drugs in elderly participants: Cardiovascular mortality and morbidity the Swedish Trial in Old Participants (STOP) Hypertension-2 study. The Lancet, 354, 1751-1756.

Lee, E.H., Kim, J.S. \& Song, M. S. (2005). Translation and validation of Champion's Health Belief Model Scale with Korean women. Cancer Nursing, 25, 391-395

Liebson P.R., Grandits G., Prineas R., Dianzumba S., Flack J. M., Cutler J. A., et al. (1993) Echocardiographic correlates of left ventricular structure among 844 mildly hypertensive men and women in the Treatment of Mild Hypertension Study TOMHS. Circulation, 87: 476-486.

Macrae, F. A., Hill, D. J., St. John, D. J. B., Ambikapathy, A., Carner, J. F, \& the Ballarat General Practitioner Researcher Group. (1984). Predicting colon cancer screening behavior from health beliefs. Preventive Medicine, 13, 115-126.

Maiman, L. A., \& Becker, M. H. (1974). The health belief model: Origins and correlates in psychological theory. Health Education Monograph, 2, 340-353.

Men, T., Brennan, P., Boffetta, P. \& Zaridze, D. (2003). Russian mortality trends for 1991-2001: analysis by cause and region. British Medical Journal, 32, 327337.

Nuesch, R., Schroeder, K., Dieterle, T., Martina, B., \& Battegay, E. (2001). Relationship between insufficient response to antihypertensive treatment and poor compliance with treatment: A prospective case-control study. British Medical Journal, 323, $142-146$. 
Rosenstock, I. M. (1974). Historical origins of the health belief model. Health Education Monograph, 2, 328-335.

Saounatsou, M., Patsi, O., Fasoi, G., Stylianou, M., Kavga, A., Economou, O. \& Mandi, P. (2002) The influence of the hypertensive patient's education in compliance with their medications. Public Health Nursing, 18, 436-442. 
Table 1

Mean scores of components in Health Belief Model

Component in the Model $\mathrm{n}$ M

SD

Motivation

Interest

62

3.10

0.84

Concern

62

2.90

1.05

Susceptibility

59

3.00

0.79

Severity

61

4.18

0.92

Benefits of

Treatment

57

3.19

0.61

Barriers

\begin{tabular}{lccc} 
Embarrassment & 62 & 1.77 & 1.12 \\
Financial burden & 62 & 2.02 & 1.05 \\
Worry & 62 & 1.82 & 1.12 \\
Discomfort & 61 & 2.38 & 1.18 \\
Inconvenience & 61 & 2.18 & 0.99 \\
Objection to the & 61 & 2.03 & 1.00 \\
Everyday routine & & & \\
mulative barriers & 61 & 2.04 & 0.78 \\
\hline
\end{tabular}

Note. Total $n=62$, some items were missed or ignored by some subjects. All calculations were based on a 5-point scale, where number 5 represented extremely, 4- quite a lot, 3 moderate amount, 2- a little, and 1- not at all. 
Table 2

Frequencies of awareness, health practices, and adherence to treatment

Category

Type of dietary advice remembered:

Lower salt in diet

Lower fat in diet

Increase fruit and vegetables

Total:

Quantity of advice remembered:

Don't remember talking with PCP about diet

1 out of 3

2 out of 3

all 3

Total

Adherence to nutritional teaching:

Not at all/Little/Moderate

25

35

60

Total

Level of Pharmacological compliance

$100 \%$

$80-99 \%$

$<80 \%$

37

61.7

40

66.7

50

83.3

60

100

6

15

24.2

11

17.7

30

48.4

62

100

Quite a lot/Extremely

58.3

100

41.7

17

39.5

9

20.9

17

39.5 
Category

n $\quad \%$

Total

43

100

Level of exercises

Moderate-to-Heavy and Vigorous exercises

Light exercises

33

54.1

Total

61 100

Frequency of exercises:

Most days of the week

33

67.3

Less than recommended by AHA

16

32.7

Total:

49

100

Knowledge about existent organ damage

No known terminal organ damage

39

65

Left ventricular hypertrophy

8

13.3

Myocardial Infarction

7

11.7

Cerebral Vascular Accident

3

5

Retinal detachment

3

5

Elevated creatinin

3

5

Total:

$60 * *$

Change in adherence over time

Improved

26

41.9

Didn't change

31

50

Decreased

5

8.1 
Category

Total

Reasons to change adherence

Improved adherence:

Health related condition:

Decline or further deterioration of health 2

I can see the blood pressure going down

1

The treatment makes me feel better

PCP related:

Change of PCP and trusting more to new PCP

Admiration to the extensive knowledge of PCP $\quad 1$

Improving self-care

Taking better care of myself

Decreased adherence:

Health related condition:

It is now difficult for me to keep up physically $\quad 1$

Total comments:

Notes: PCP stands for primary care provider

* many people employed 2 or 3 different methods of relaxation

**some people reported more than one complication of HTN 
Table 3

Significant correlations among variables

Category

r p-value

Education

Reading for relaxation

$0.267 \quad 0.036$

Motivation (interest)

Level of exercises

0.348

0.006

Overall adherence

0.352

0.005

Susceptibility

All complications

0.273

0.036

Severity

Missed number of medications

$-0.606$

0.000

Benefits of treatment

Rate of Left Ventricular Hypertrophy

0.285

0.035

Embarrassment

Frequency of exercises

$-0.315$

0.028

Overall compliance

$-0.362$

0.004

Financial burden

Remembering salt restriction

0.300

0.020

Remembering low-fat restriction

0.340

0.008

Worry about compliance

Number of medications prescribed daily

0.336

0.009 
Category

Frequency of exercises

Overall compliance

Discomfort

Walking 30 minutes for relaxation

Frequency of exercises

Inconvenience

Frequency of exercises

Compliance with diet

Rate of LVH

Presence of complications of HTN

Change in compliance r

$-0.317$

$-0.334$

0.008

p-value

0.027

$-0.417$

0.001

$-0.303$

0.036

$-0.364$

0.011

$0.324 \quad 0.013$

0.372

0.003

Note: Significance level was always less then 0.05 , actual significance level is reported as p-value, where 0.000 means p-value is less than 0.001 . MI-myocardial infarction, CVACerebral-Vascular Accident, LVH-Left Ventricular Hypertrophy. 